\title{
Semi Fractal Three Leaf Clover-Shaped CPW Antenna for Triple Band Operation
}

\author{
M. Naser-Moghadasi ${ }^{1}$, R. A. Sadeghzadeh ${ }^{2}$, R. Khajeh Mohammad Lou ${ }^{1}$, B. S. Virdee ${ }^{3}$ and \\ Tohid Aribi ${ }^{1}$
}

${ }^{1}$ Faculty of Eng., Science and Research Branch, Islamic Azad University, Tehran, Iran; Corresponding

${ }^{2}$ Faculty of Electrical and Computer Eng, K. N. Toosi University of Technology, Tehran, Iran

${ }^{3}$ London Metropolitan University, Center for Communications Technology, Faculty of Computing, 166220 Holloway Road, London N7 8DB, United Kingdom

\begin{abstract}
This article presents a unique and compact coplanar waveguide (CPW) antenna that exhibits triband operation with circular polarization. The single antenna was designed to operate simultaneously in the following bands: WiMAX (3.3-3.6 GHz), WLAN (5.15-5.825 GHz), ITS $(5.795-6.400 \mathrm{GHz})$ and ITU-R $(7.725-8.5 \mathrm{GHz})$. The realization of the tri-band antenna was achieved by employing two semi fractal ring patches resembling the shape of a three leaf clover, and by introducing a pair of symmetrical L-shaped slits in its ground-plane. The antenna's physical parameters were investigated to fully understand their affect on the antenna's performance. The salient parameters obtained from this analysis enabled the optimization of the antenna's overall characteristics. The design concept was confirmed by fabricating the antenna prototype and measuring its characteristics. The proposed antenna has dimensions of $20 \times 20 \times 1$ $\mathrm{mm}^{3}$. Measured results show the antenna exhibits circular polarization in WiMAX and ITU-R bands, and linear polarization in the WLAN band. The antenna radiates omnidirectionally in the H-plane, and approximately bi-directionally in the E-plane. In addition, the antenna presents gain over the tri-band.
\end{abstract}

Keywords: Fractals, triple band, coplanar-waveguide (CPW) antenna, circular polarization 


\section{Introduction}

In recent years, the use of high data rate wireless communications has proliferated exponentially, making substantial demands on bandwidth and interoperability within the physical layer, which has resulted in wireless devices expected to function in different multiband environments to accommodate various communication standards [1]. The key component and challenge of such ultra-wideband systems include the design of a single antenna for multiband operation, which possesses characteristics of good impedance matching, omnidirectional radiation patterns, and stable gain performance. In addition, the antenna needs to be compact in size, amenable for easy integration with the radio frequency front-end circuitry, and of low manufacturing cost for consumer electronics applications. Among the well-known multiband antenna prototypes, the planar and coplanar monopole antennas of various configurations have become popular in the implementation of wireless systems because they provide a cost effective and low profile antenna designs with omnidirectional radiation patterns. Multiband operation of antennas can be achieved by using multi-resonators so that each resonator radiates independently at each operating frequency [2]-[4]. However, it has been found that using these multiband design techniques, the antenna characteristics could not be easily adjusted due to the effects of mutual couplings between resonators. Furthermore, the difficulty in designing such antennas is challenging when the size of the antenna needs to be reduced and the number of operating frequency bands needs to be increased [5],[6].

Various antenna designs have been proposed and reported over the years, which can be utilized for multiband applications [7]. Such antennas include configurations of inverted-F, CPW fed slot, and fractal geometries. These antennas have been investigated for wireless local area networks (WLANs), Worldwide Interoperability for Microwave Access (WiMAX), ITS and ITU-R [8]-[11]. The implementation of these antennas can result in drawbacks, namely: the use of parasitic elements to generate different resonance modes that can increase the antenna size; mutual coupling between signal paths of various lengths; complex fabrication process; and lack of circular polarization (CP) in resonance modes generated [12],[13]. Circular polarization enables uninterrupted communications of wireless systems as the correct orientation of the transmitter and receiver antennas is unimportant. In addition, CP can overcome issues related 
with multipath fading to enhance system performance, and can also provide better mobility and weather penetration than linearly polarized antennas [14]-[17].

In this article, a novel compact CPW-fed triple band antenna is proposed with circular polarization in its two resonance bands. Multiband functionality is achieved using a combination of semi fractals patch rings resembling a three leaf clover, and dual symmetrical L-shaped slits in the antenna's ground-plane. Operational bands covered simultaneously by the antenna include: WiMAX (3.3-3.6 GHz), WLAN (5.15-5.825 GHz), ITS (5.795-6.400 GHz) and ITU-R (7.7258.5 GHz). The resonance band centered at WiMAX is associated with the outer semi fractal clover shaped ring of length corresponding to one quarter guided-wavelength. The resonance band covering WLAN and ITS systems is attributed to the inner semi fractal clover shaped ring, and the ITU-R band is achieved by etching out dual symmetrical L-shaped slots in the groundplane. The proposed antenna provides circular polarization characteristics in WiMAX and ITU-R bands with a CP bandwidth $13 \%$ and $12 \%$, respectively. The proposed method is validated through simulation, fabrication and measurement. Details of the antenna design and comparison between the experimental and simulation results are presented. The article is organized as follows: Section II describes the proposed multiband antenna configuration; Section III presents the simulation results of the proposed antenna; Section IV reports the measurement results; and finally Section V summarizes the study.

\section{Antenna Design}

The geometry and physical parameters describing the proposed antenna is shown in Fig. 1. It consists of a patch constituted from a pair of semi fractal rings resembling a three leaf clover. The antenna's rectangular ground-plane is etched on the same side of printed circuit board (PCB) with dielectric constant of $4.4, \tan \delta=0.024$ and substrate thickness of $1 \mathrm{~mm}$. The dimension of the substrate is $20 \times 20 \mathrm{~mm}^{2}$, and the coplanar waveguide feed has a width $W_{\mathrm{f}}=3 \mathrm{~mm}$, which corresponds to a characteristic impedance of $50 \Omega$. The ground-plane is modified by etching within it a pair of symmetrical L-shaped dielectric slits in the vicinity of the patch. The distance between the inner and outer semi fractal patches and the L-shaped slit dimensions are main factors of the antenna that dictate its multiband functionality. Fig. 2 depicts the three systematic steps taken to develop the proposed antenna, namely: 
Step-1 (Ant.0): Create a CPW feed-line forming the trunk for the inner clover shaped ring patch that determines the creation of the WLAN band.

Step-2 (Ant.1): Add an outer clover shaped ring patch that determines the creation of the WiMAX band.

Step-3 (Ant.2): Apply ground-plane modification in order to create a resonance mode at the ITU-R band.

The antenna dimensions were optimized by parametric study using Ansoft's High Frequency Structure Simulator (HFSSv.15). Optimal parameters of the proposed antenna are: $W_{\text {sub }}=20 \mathrm{~mm}$, $L_{\mathrm{sub}}=20 \mathrm{~mm}, W_{\mathrm{f}}=3 \mathrm{~mm}, L_{\mathrm{f}}=6.8 \mathrm{~mm}, W_{\mathrm{g}}=8.2 \mathrm{~mm}, L_{\mathrm{g}}=3.5 \mathrm{~mm}, W_{\mathrm{s}}=3.0 \mathrm{~mm}, L_{\mathrm{s}}=2.5 \mathrm{~mm}, W_{\mathrm{d}}=$ $2 \mathrm{~mm}, g=0.4 \mathrm{~mm}, L_{\mathrm{d}}=1 \mathrm{~mm}, W_{\mathrm{p}}=0.6 \mathrm{~mm}, L_{\mathrm{p} 1}=3 \mathrm{~mm}, W_{\mathrm{p} 1}=2.75 \mathrm{~mm}, L_{\mathrm{p} 2}=4.4 \mathrm{~mm}, W_{\mathrm{p} 2}=4.5$ $\mathrm{mm}$.

\section{ANTENNA DESIGN AND PARAMETRIC STUDY}

In this section, the CPW fed antenna structure's parameters is investigated. The effect of individual parameters on the antenna's performance was ascertained by changing the parameter in question while keeping all other parameters fixed [16]. The antenna's dimensions were determined through the optimization process. The simulated results are obtained using the Ansoft High-Frequency Structure Simulator version 15. The antenna was constructed to evaluate its numerical and experimental results of the input impedance and radiation characteristics.

The evolution of the proposed triple-band antenna design and its corresponding simulated $S_{11}$ response are presented in Figures 3-5. It was observed that for Ant.0, the ground-plane length $\left(L_{\mathrm{g}}\right)$ has a major effect on the antenna's impedance matching property. The effect of varying the length of the ground-plane $\left(L_{\mathrm{g}}\right)$ is shown in Fig. 3. It is clear that the resonance frequency is sensitive to this parameter, and a small deviation from the optimum value can lead to deviation from the desired band. The operating frequency band corresponding to Ant. 0 is confined between 4.7-6.4 GHz with a S1 $1 \leq-10 \mathrm{~dB}$ that covers WLAN $(5.15-5.825 \mathrm{GHz})$ and ITS $(5.795-$ $6.4 \mathrm{GHz}$ ) bands when the optimum value of $L_{\mathrm{g}}=3.5 \mathrm{~m}$. By introducing the outer clover shaped ring, a second resonance mode is established at the WiMAX band. The gap between the inner 
and outer rings $\left(L_{\mathrm{d}}\right)$ is an important parameter for Ant.1. Fig. 4 shows the effect of $L_{\mathrm{d}}$ on the $\mathrm{S}_{11}$ response of Ant.1, while keeping $L_{\mathrm{g}}$ fixed at its optimum value of $3.5 \mathrm{~mm}$. The results show that outer signal path does not have any effect on the frequency band of the inner resonance mode, however it influences the center frequency of the second resonance mode at the WiMAX (3.3$3.6 \mathrm{GHz}$ ) band. The optimum value of $L_{\mathrm{d}}$ is found to be $1 \mathrm{~mm}$. The third resonance mode at the ITU-R band is produced by cutting out symmetrical L-shaped slits in the ground-plane, as shown in Fig. 2. Fig. 5 depicts the effect of the horizontal section of L-shaped slot $\left(W_{\mathrm{s}}\right)$ and the width $\left(W_{\mathrm{d}}\right)$ of the L-shaped slit form the edge of substrate on the antenna's $\mathrm{S}_{11}$. The optimum values obtained from the study are: $W_{\mathrm{s}}=3.0 \mathrm{~mm}$ and $W_{\mathrm{d}}=2.0 \mathrm{~mm}$ to realize the ITU-R band $(7.725-8.5$ GHz). Fig. 6 depicts the $S_{11}$ response for the three antenna stages (Ant.0, Ant.1, and Ant.2). As shown, Ant.0 covers the frequency bands of WLAN and ITS. Adding an outer clover shaped ring to Ant.0 (Ant.1) creates a new resonance at around $3.5 \mathrm{GHz}$ (WiMAX). The other resonances (ITU-R) generated by stages Ant.0 and Ant.1 remain unaffected by cutting out L-shaped slits on ground-plane.

\section{Experimental Results}

To verify the proposed design, a prototype of the antenna was manufactured using optimal values, and its performance evaluated using Agilent 8722ES vector network analyzer. Measured and simulated reflection-coefficient of the proposed antenna is shown in Fig. 7. This figure shows that there is generally good correlation between the measurement and simulation results. The measured results show $\mathrm{S}_{11} \leq-10 \mathrm{~dB}$ are obtained between $2.95-4.0 \mathrm{GHz}, 4.9-6.55 \mathrm{GHz}$ and 7.35-8.55 GHz, which meet the frequency and bandwidth specification requirements of WiMAX, WLAN, ITS and ITU-R. The small discrepancy between measured data and the simulated results are attributed to fabrication tolerance and SMA connector. The measured axialratio as a function of frequency plot in Fig. 8 shows the measured circular polarization bandwidth is $13 \%$ for a frequency range between 3.25 to $3.68 \mathrm{GHz}$, and $12 \%$ between 7.72 to 8.68 GHz, which are inside the respective impedance bands of WiMAX and ITU-R. The measured peak antenna gain across the desired bands, i.e. WiMAX, WLAN, ITS and ITU-R, is shown in Fig. 9. The proposed antenna exhibits satisfactory and adequate gain level in these bands. Table I lists the band of the mobile communication standards which are excited by Ant. 0 , Ant. 1, and Ant. 2. 
The two principle planes representing the radiation-patterns of fabricated antenna are the yz-plane (E-plane) and xz-plane (H-plane). The measured radiation-patterns of the antenna at the center frequency of each band are shown in Fig. 10 and Fig. 11. Fig. 10 shows the measured right-handed circular polarized (RHCP) and the left-handed circular polarized (LHCP) radiation patterns for phi equal to 0 degree and 90 degrees at $3.5 \mathrm{GHz}$ in the WiMAX band and $8 \mathrm{GHz}$ in ITU-R band. Also, the measured radiation-patterns of the antenna in both the E-plane and $\mathrm{H}$ plane at $5.5 \mathrm{GHz}$, is shown in Fig. 11. The antenna has an omnidirectional radiation-pattern in $\mathrm{H}$ plane and approximately bi-directional in the E-plane.

\section{Conclusion}

A single CPW-fed semi fractal antenna was described that can operate simultaneously over multiple bands, i.e. WiMAX, WLAN, ITS and ITU-R. The antenna consists of two semi fractal rings whose shape resembles a three leaf clover. Embedded in the antenna's ground-plane includes dual symmetrical L-shaped slits that determine its resonant modes. The antenna has dimensions of $20 \times 20 \times 1 \mathrm{~mm}^{3}$. Measured results confirm the antenna has a good impedance match across its operational bands, and exhibits circular polarization functionality over the WiMAX and ITU-R bands with 3-dB axial-ratio bandwidth reaching 98\% for which the S11 $\leq$ $10 \mathrm{~dB}$. The antenna's radiation pattern is omnidirectional in the H-plane and approximately bdirectional in the E-plane, and its gain is stable over its operational bands. These features make the antenna suitable for multiband wireless systems that require low-profile antennas. 


\section{Reference}

[1] M. Naser-Moghadasi, R. A. Sadeghzadeh, M. Fakheri, T. Aribi, T. Sedghi, and B. S. Virdee, "Miniature Hook-Shaped Multiband Antenna for Mobile Applications," IEEE Antenna Wireless Propag. Lett. 11 (2012), 1096-1099.

[2] Liu, Z.-Y., Yin, Y.-Z., Zheng, S.-F., Hu, W., Wen, L.-H., "A Compact CPW-Fed Monopole Antenna with a U-Shaped Strip and a Pair of L-Slits Ground for WLAN and WIMAX Application," Progress in Electromagnetic Research Letters 16 (2010), 11-19.

[3] Mahatthanajatuphat, C., Wongsin, N., Akkaraethalin, P., "A Multiband Monopole Antenna with Modified Fractal Loop Parasitic," Int. Symposium on Antenna and Propagation (2010), 57-74.

[4] Hsieh, H.-W., Lee, Y.-C., Tiong, K.-K., Sun, J.-S., "Design of a Multiband Antenna for Mobile Handset Operations," IEEE Antennas and Wireless Propagation Letter 8 (2009), 200-203.

[5] M. Naser-Moghadasi, R. Sadeghzadeh, L. Asadpor, and B. S. Virdee, "A Small Dual-Band CPW-Fed Monopole Antenna for GSM and WLAN Applications," IEEE Antenna Wireless Propag. Lett. 12 (2013), 508-511.

[6] P. Wang, G. J. Wen, Y. J. Huang and Y. H. Sun, "Compact Meander T-shaped Monopole Antenna for Dual-Band WLAN Applications," Int. J. of RF Microwave Computer-Aided Eng., 23 (2013), 67-73.

[7] C. Mahatthanajatuphat and P. Akkaraekthalin, "Bidirectional Multiband Antenna with Modified Fractal Slot Fed by CPW," Progress in Electromagnetics Research, PIER 95 (2009), 59-72.

[8] M. N. Mou Kehn, O. Quevedo-Teruel and E. Rajo-Iglesias, "Reconfigurable Loaded Planar Inverted-F Antenna Using Varactor Diodes," IEEE Antenna Wireless Propag. Lett. 10 (2011), 466- 468.

[9] M. N. Mahmoud and R. Baktur, "A Dual Band Microstrip-Fed Slot Antenna," IEEE Trans. Antenna Propag. 59 (2011), 1720-1724.

[10] M. Rahanandeh, A.S. Noor Amin, M. Hosseinzadeh, P. Rezai, and M. Sadegh Rostami, "A Compact Elliptical Slot Antenna for Covering Bluetooth/WiMAX/WLAN/ITU," IEEE Antenna Wireless Propag. Lett. 11 (2012), 857-860.

[11] Joong Han Yoon and Gyung-Suk Kil, "Compact Monopole Antenna with Two Strips and a Rectangular-Slit Ground Plane for Dual-Band WLAN/WiMAX Applications," Microwave Opt. Technol. Lett. 54 (2012), 1559-1566.

[12] P. Xu, Z.-H. Yan, and C. Wang, "Multi-Band Modified Fork-Shaped Monopole Antenna with Dual L-Shaped Parasitic Plane," Electron. Lett. 46 (2011), 364-365.

[13] Y.-C. Lee and J.-S. Sun, "A New Printed Antenna for Multiband Wireless Applications," IEEE Antennas Wireless Propag. Lett. 8 (2009), 402-405.

[14] N. Felegari, J. Nourinia, C. Ghobadi, and J. Pourahmadazar, "Broadband CPW-Fed Circularly Polarized Square Slot Antenna with Three Inverted-L-Shape Grounded Strips," IEEE Antenna Wireless Propag. Lett. 10 (2011), 274-277.

[15] Can-Hui Chen and E. K. N. Yung, "Dual-Band Circularly-Polarized CPW-Fed Slot Antenna with a Small Frequency Ratio and Wide Bandwidths," IEEE Trans. Antenna Propag. 59 (2011), 1379-1384.

[16] M. Naser-Moghadasi, R. A. Sadeghzadeh, T. Sedghi, T. Aribi, and B. S. Virdee, "UWB CPW-Fed Fractal Patch Antenna With Band-Notched Function Employing Folded TShaped Element,” IEEE Antenna Wireless Propag. Lett. 12 (2013), 504-507. 


\section{Figure Caption}

Figure 1 Geometry of the proposed triple band CPW fed antenna

Figure 2 Steps taken in the evolution of the proposed antenna

Figure 3 Simulated reflection-coefficient response for Ant.0 as a function of parameter $\mathrm{Lg}_{\mathrm{g}}$

Figure 4 Simulated reflection-coefficient response for Ant.1 as function of parameter $L_{d}$

Figure 5 Simulated reflection-coefficient response for Ant. 2 as a function of horizontal section length $\left(\mathrm{W}_{\mathrm{s}}\right)$ of the L-shaped slit and length $\left(\mathrm{W}_{\mathrm{d}}\right)$ from the edge of the ground-plane.

Figure 6 Simulated reflection-coefficient response for Ant. 0, Ant.1, and Ant. 2

Figure 7 Measured and simulated reflection-coefficient response for Ant. 2

Figure 8 Measured and simulated axial-ratio for the proposed antenna.

Figure 9 Measured antenna peak gain across the three impedance bandwidths?

Figure 10 Measured LHCP and RHCP radiation patterns of the proposed antenna at: (a) 3.5 $\mathrm{GHz}$, and (b) $5.5 \mathrm{GHz}$

Figure 11 Measured H-Plane and E-Plane radiation patterns of the antenna at 5.5 GHz.

\section{Table Caption}

Table 1 Characterizing Parameter Values of the Proposed Antenna 


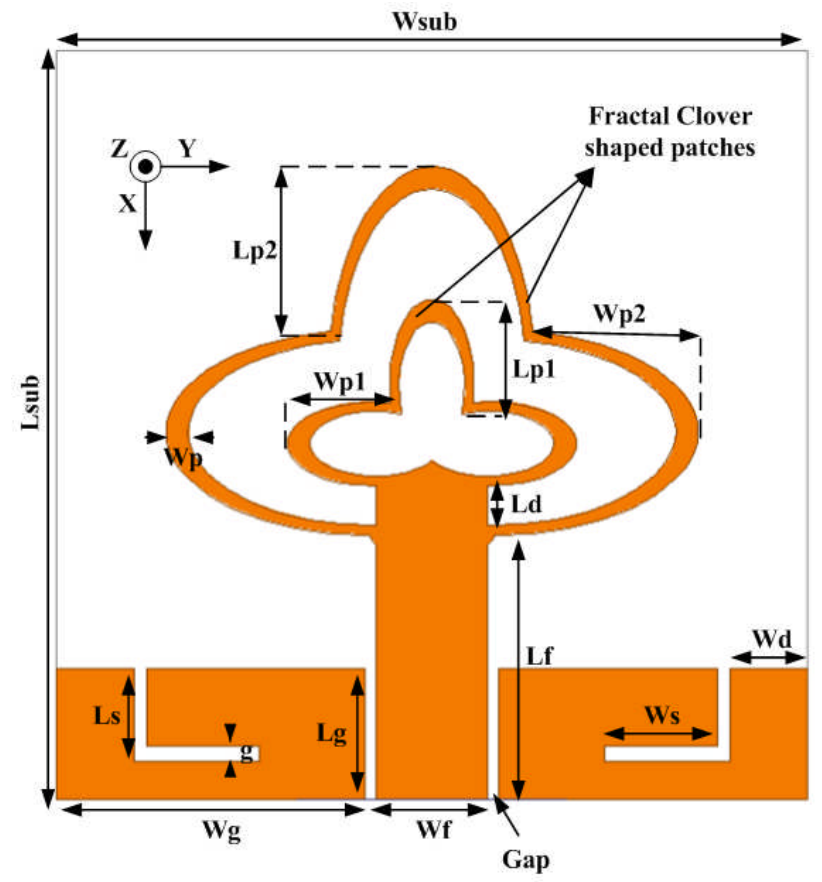

Figure 1

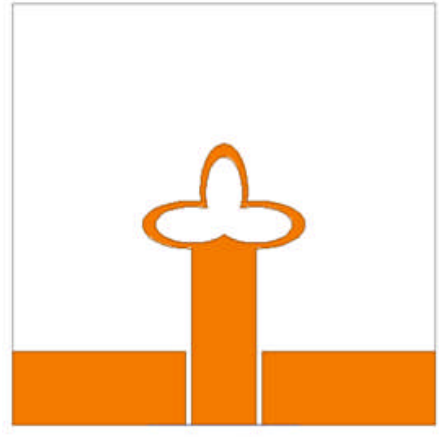

Ant.0

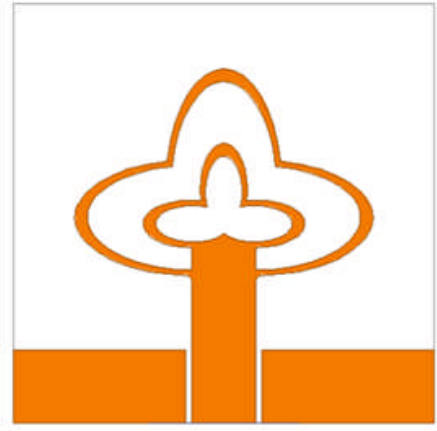

Ant.1

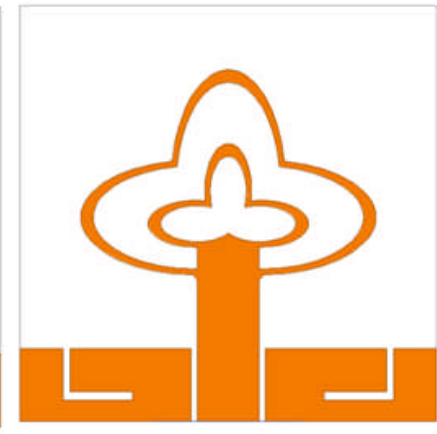

Ant.2

Figure 2 


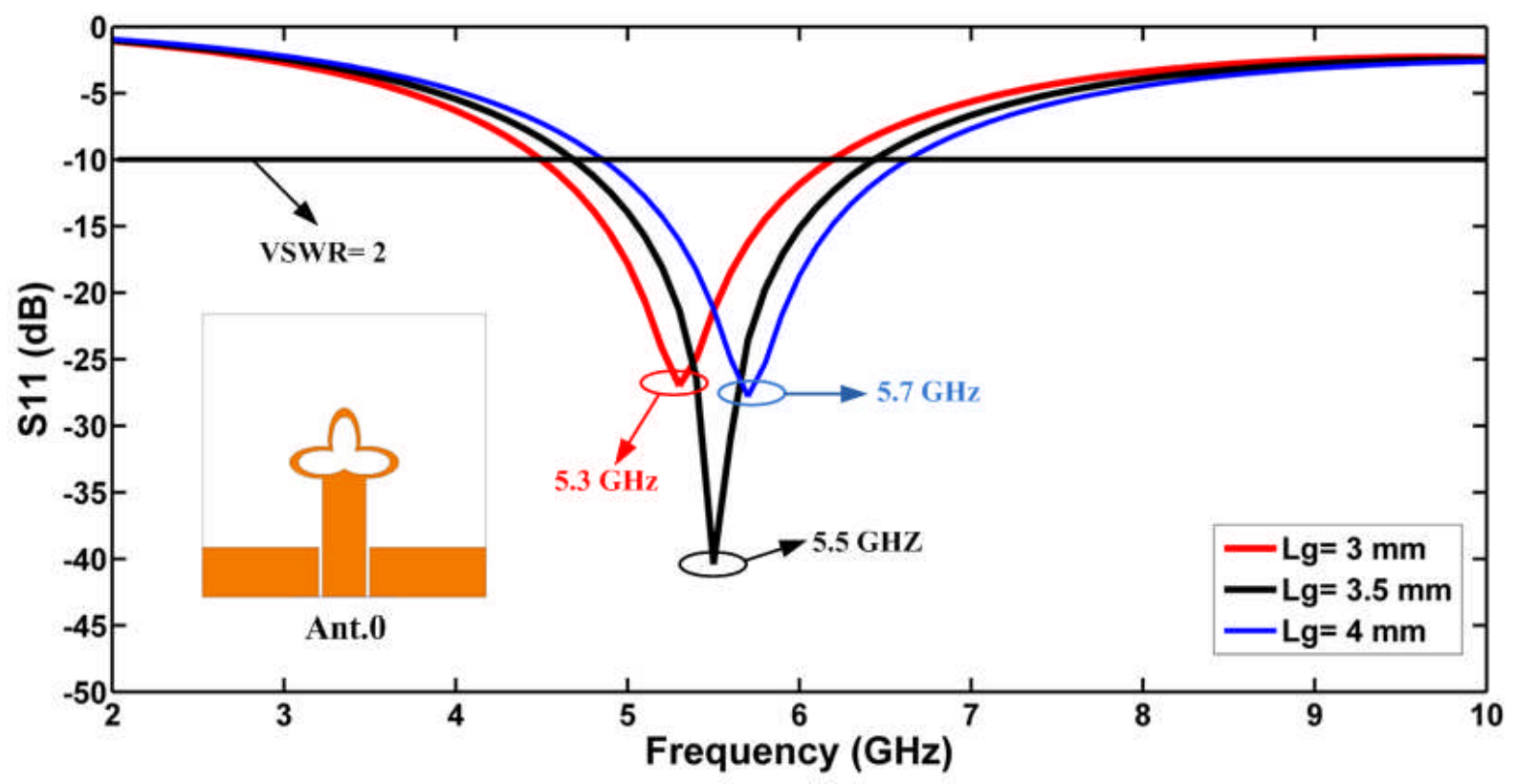

Figure 3

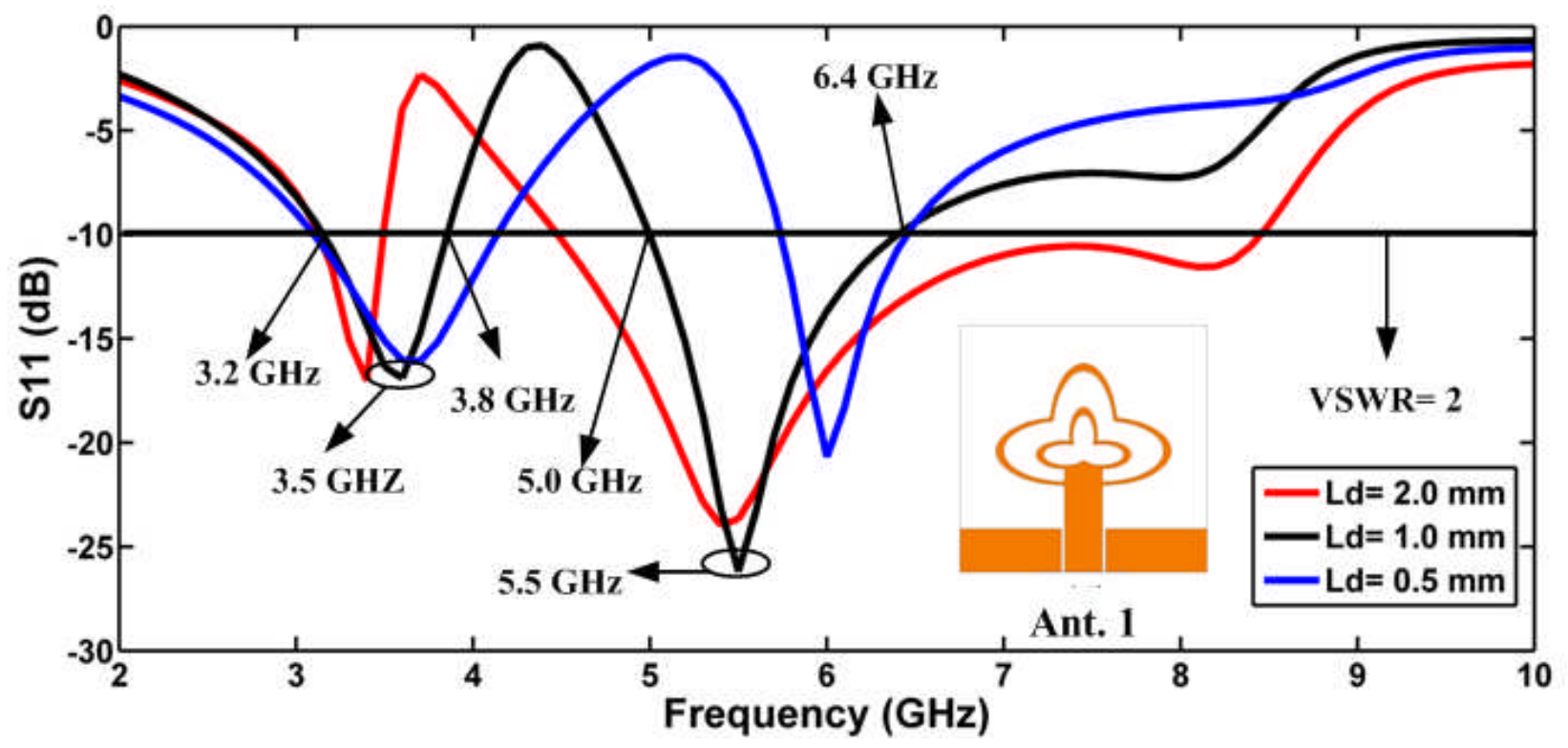

Figure 4 


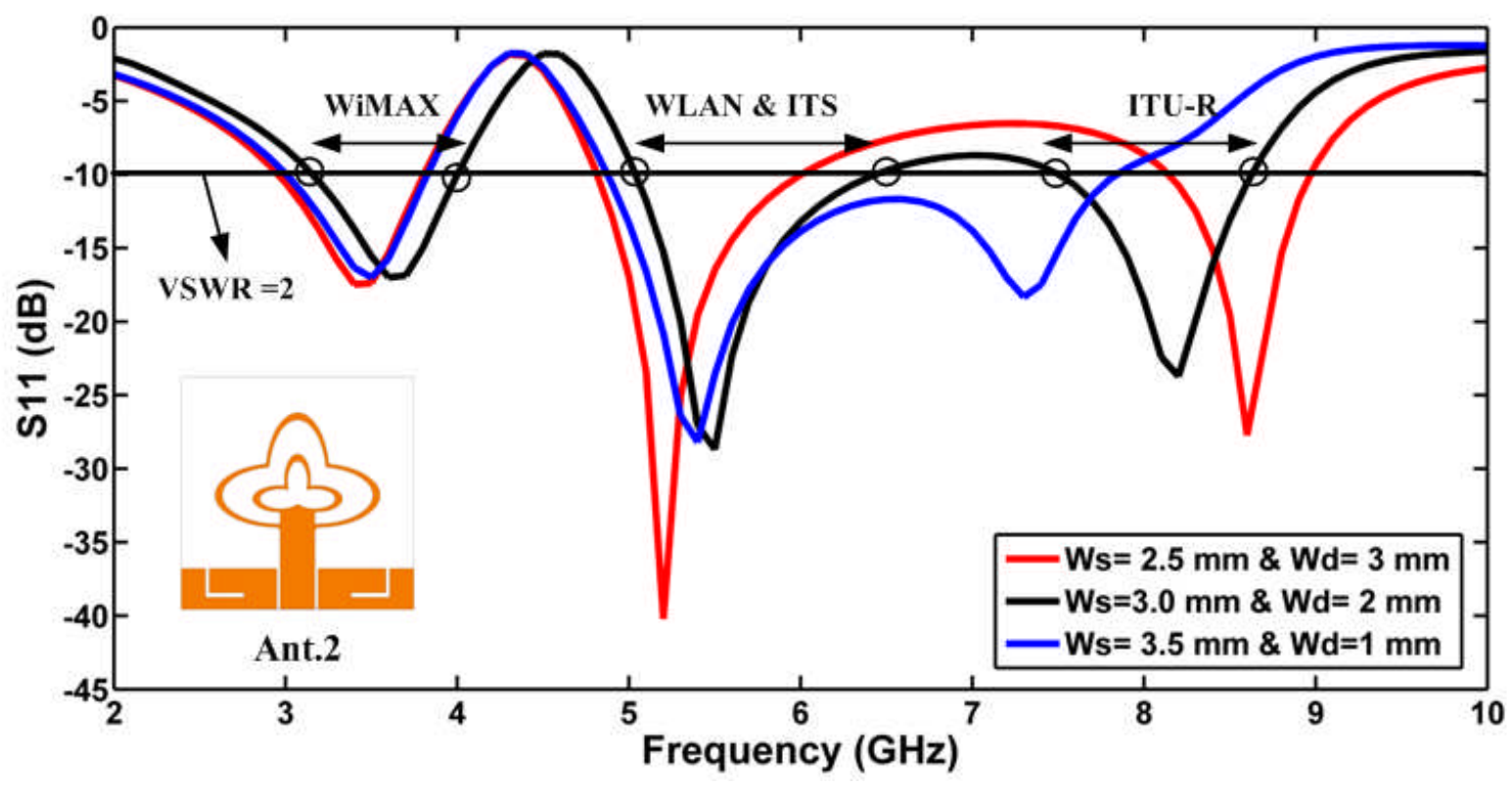

Figure 5

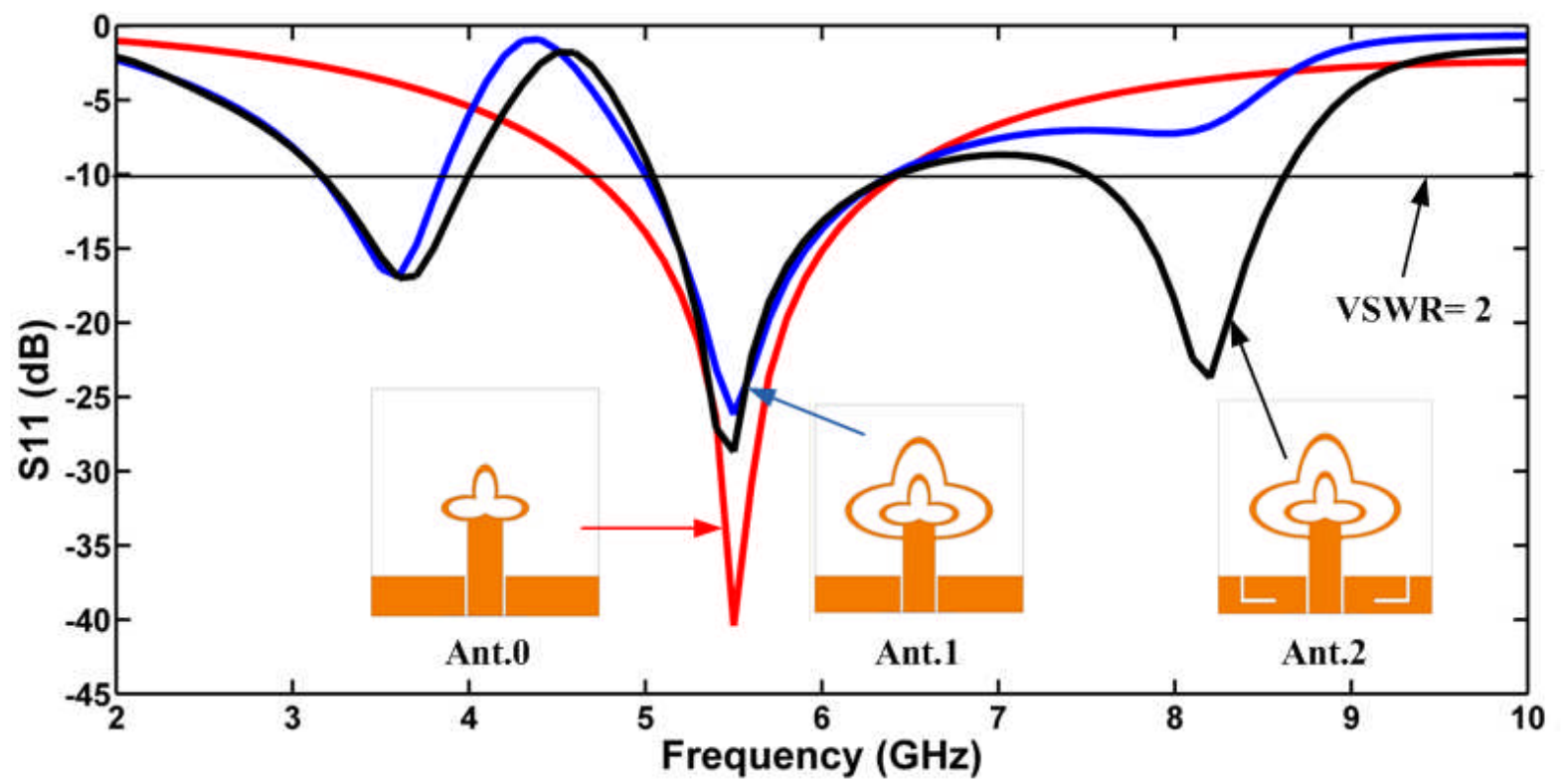

Figure 6 


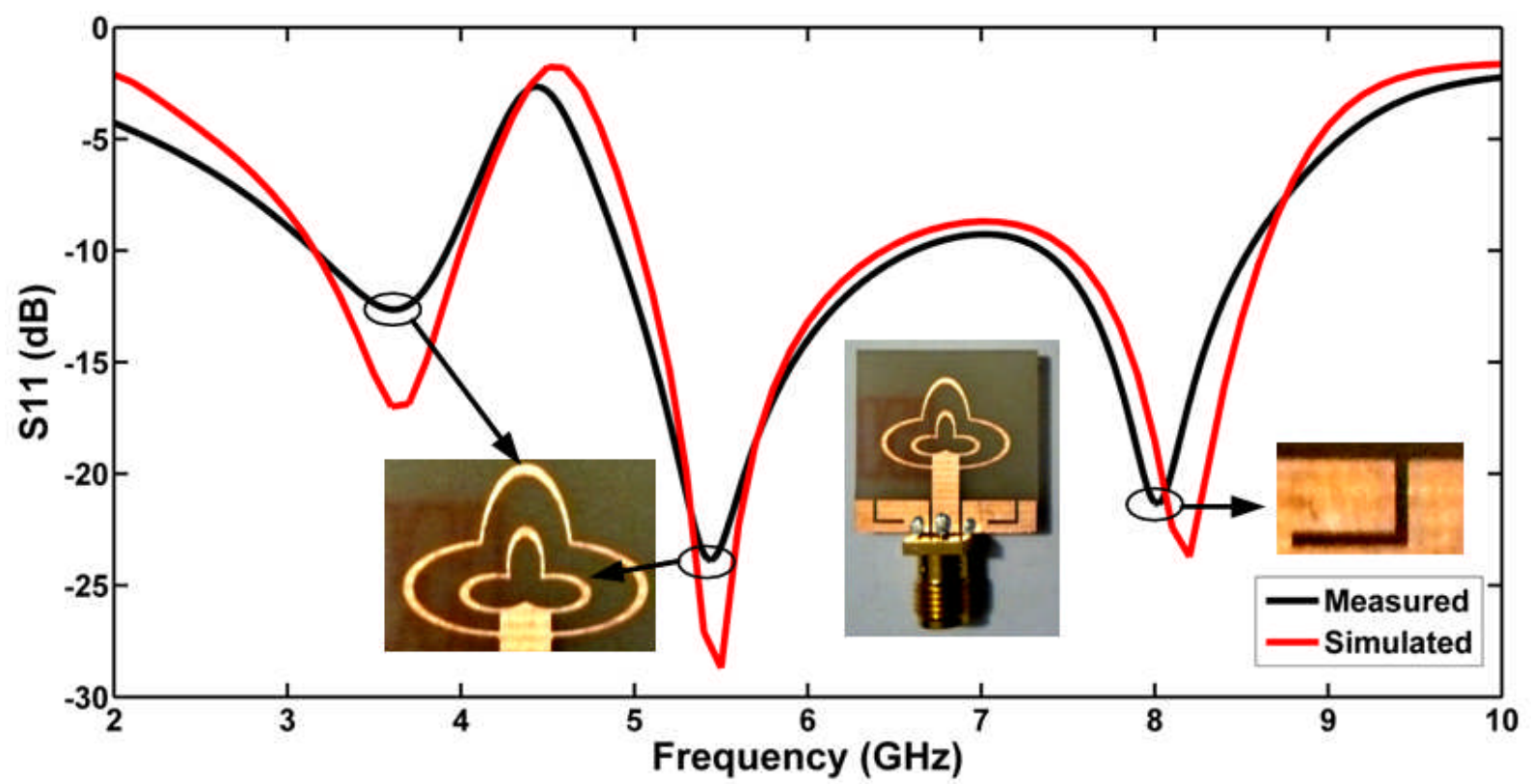

Figure 7

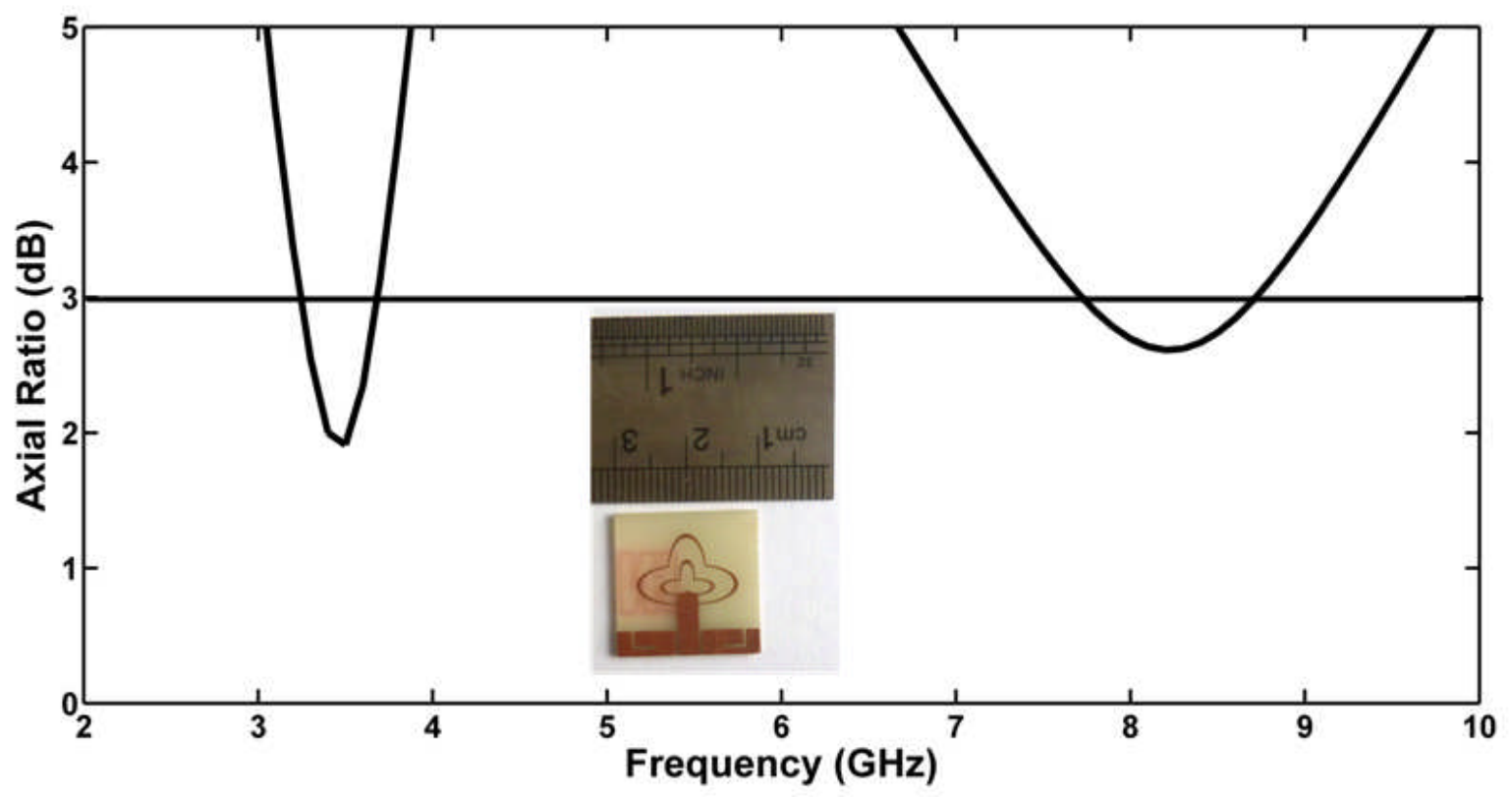

Figure 8 


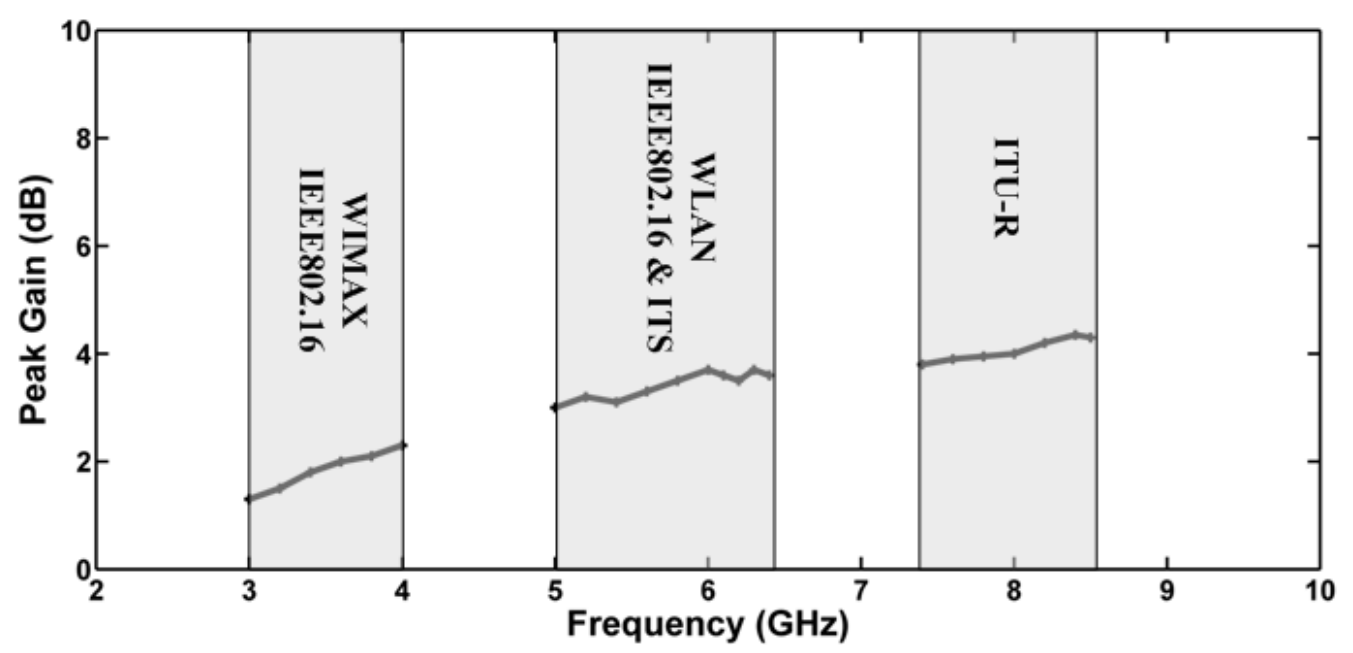

Figure 9

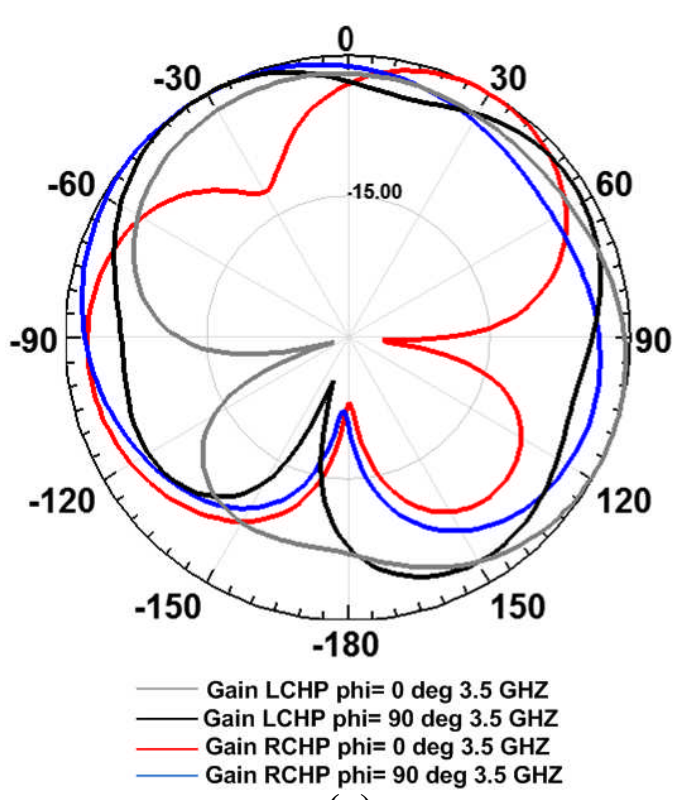

(a)

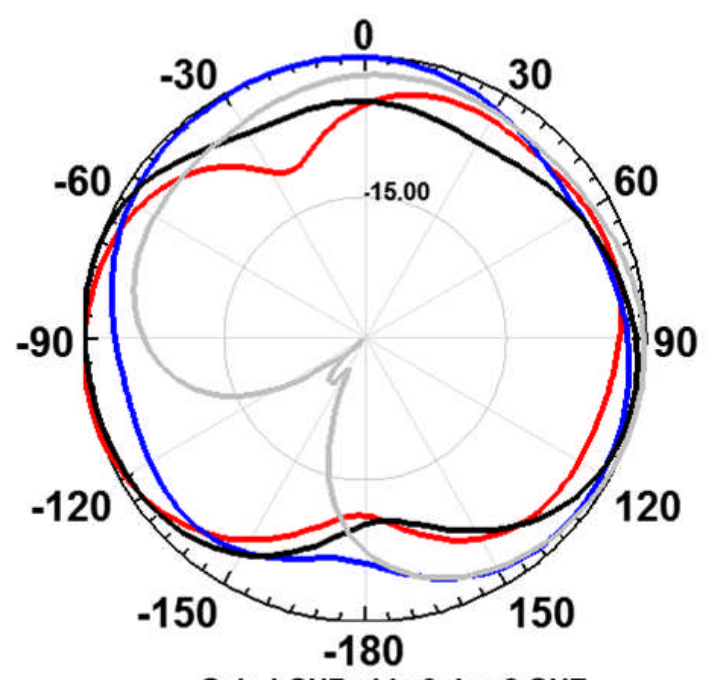

Gain LCHP phi $=0$ deg $8 \mathrm{GHZ}$

Gain LCHP phi $=90$ deg $8 \mathrm{GHZ}$ Gain RCHP phi $=0$ deg $8 \mathrm{GHZ}$ Gain RCHP phi $=90 \operatorname{deg} 8 \mathrm{GHZ}$

(b)

Figure 10 


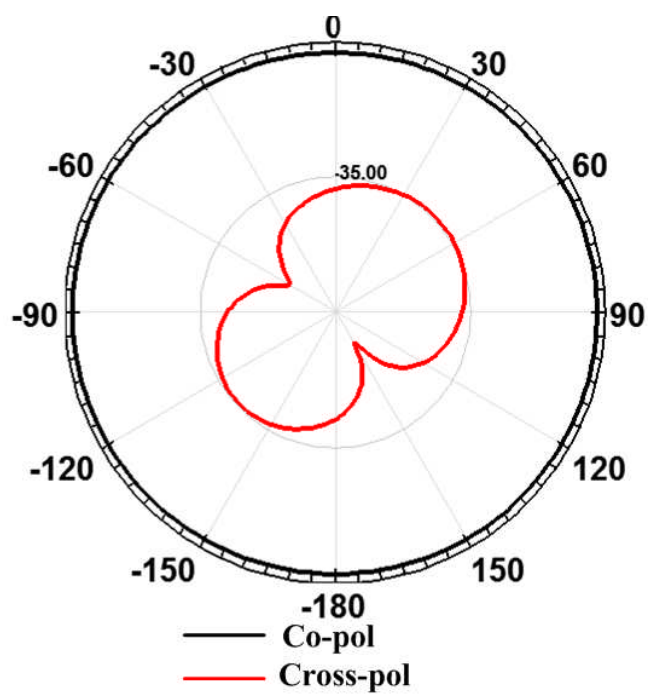

H-plane at 5.5 GHz

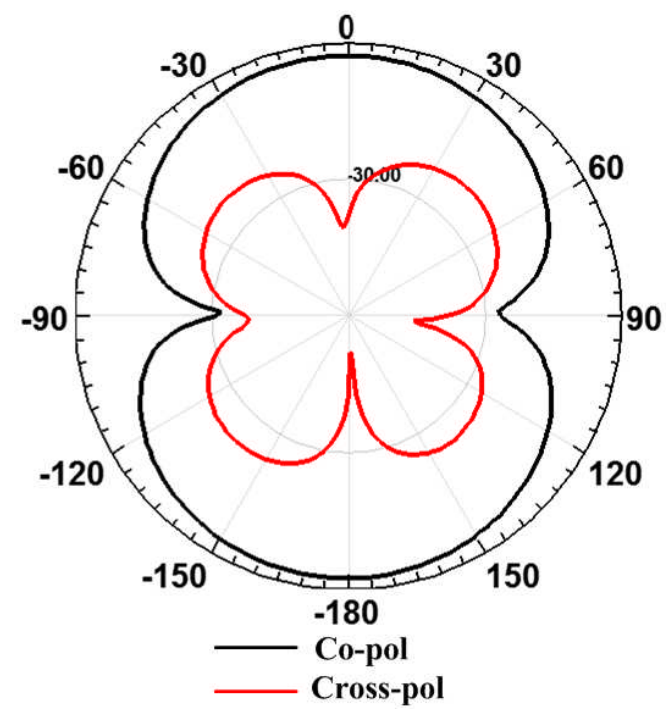

E-plane at 5.5 GHz

Figure 11

Table I

\begin{tabular}{|c|c|c|c|c|c|}
\hline \multirow[t]{2}{*}{ Antenna } & \multirow{2}{*}{$\begin{array}{l}\text { Frequency range }(\mathrm{GHz}) \\
\text { for } S_{11} \leq-10 \mathrm{~dB}\end{array}$} & \multicolumn{4}{|c|}{ Mobile communication standards } \\
\hline & & WiMAX & WLAN & ITS & ITU-R \\
\hline Ant. 0 (sim.) & $4.7-6.6$ & $x$ & $\sqrt{ }$ & $\sqrt{ }$ & $x$ \\
\hline Ant. 1 (sim.) & $\begin{array}{l}3.2-6.4 \\
5.0-6.4\end{array}$ & $\sqrt{ }$ & $\sqrt{ }$ & $\sqrt{ }$ & $x$ \\
\hline $\begin{array}{l}\text { Ant. } 2 \text { (meas. } \\
\& \text { sim.) }\end{array}$ & $\begin{array}{l}2.95-4.00 \text { (meas.) } \\
3.05-4.10 \text { (sim.) } \\
4.90-6.55 \text { (meas.) } \\
5.10-6.40 \text { (sim.) } \\
7.35-8.55 \text { (meas.) } \\
7.50-8.61 \text { (sim.) }\end{array}$ & $\sqrt{ }$ & $\sqrt{ }$ & $\sqrt{ }$ & $\sqrt{ }$ \\
\hline
\end{tabular}

